\title{
A Qualitative Content Analysis of Knowledge Storage in Nursing Education System
}

\author{
Hossein Karimi Moonaghi ${ }^{1,2}$; Mohammad Reza Ahanchian ${ }^{3}$; Zahra Marzieh Hassanian ${ }^{4,}$ \\ ${ }_{1}^{1}$ Department of Medical and Surgical, Faculty of Nursing and Midwifery, Mashhad University of Medical Sciences, Mashhad, IR Iran \\ 2 Department of Medical Education, Faculty of Medicine, Mashhad University of Medical Sciences, Mashhad, IR Iran \\ 3 Faculty of Education and Psychology, Ferdowsi University of Mashhad, Mashhad, IR Iran \\ ${ }^{4}$ Faculty of Nursing and Midwifery, Mashhad University of Medical Sciences, Mashhad, IR Iran \\ ${ }^{*}$ Corresponding Author: Zahra Marzieh Hassanian, Department of Post-Graduation, Faculty of Nursing and Midwifery, Mashhad University of Medical Sciences, Mashhad, IR Iran. \\ Tel: +98-9188129963, E-mail: hassanian1226@yahoo.com
}

Received: July 7, 2014; Revised: August 11, 2014; Accepted: August 30, 2014

\begin{abstract}
Background: The need for effective management of intellectual and academic assets is constantly growing. The nursing educational system should be considered as a storage of knowledge since it is deposited in the nursing educational system in the form of intellectual investment.

Objectives: The purpose of the present study was to explore nursing knowledge storage in the nursing educational system.

Materials and Methods: The participants of this study consisted of eight nursing educators and five students. The inductive content analysis method was used in this research. Participants were interviewed through the semi-structured method. Data analysis was done by five stage framework approaches. The trustworthiness of the study was ensured through validity and acceptability criteria.

Results: Data analysis showed that nursing educators and students were involve in teaching and learning activities by storing knowledge in subjective and objective forms. Knowledge was gained through the different educational activities of the nursing educators and through contact with their peers. Moreover, the nursing students gained knowledge for better learning and a more knowledgeable and advanced performance with the help of the educators.

Conclusions: This study revealed the main components of knowledge storage. An enhanced preservation of explicit knowledge is recommended in the nursing educational system so that in the future, students and educators can easily access the same knowledge from storage sources and not from individuals who might be carrying only a single experience of the subject.
\end{abstract}

Keywords:Education; Knowledge; Knowledge Management; Nursing; Qualitative Research

\section{Background}

In recent years, academic societies have understood the value of intellectual capital (1); however, it was only recently that they have directed their focus to the organization as an entity for storing knowledge (2). Most scientists agree that the essence of knowledge can be defined as justified, true belief (3). Knowledge management (KM) is a series of coordinated, precise, and continuous efforts to manage organizational knowledge and to leverage it (4). Knowledge can also be defined as the self-explained belief in an individual that increases his or her potential for performing activities (5). Another study divided nursing knowledge into empirical, ethical, aesthetic, and personal knowledge (6). Nursing knowledge is mostly constituted of tacit knowledge rather than explicit knowledge (7). Tacit knowledge could be considered as the know-how and is cognitive in dimension (8) whereas explicit knowledge is a more formal type of knowledge (9). Academic knowledge includes both tacit as well as explicit knowledge (10). Explicit knowledge is acquired from critique implicit knowledge (11). KM is a process for acquiring, verifying, and classifying knowledge-related assets acquired from the staff and nurse educators of faculty or from other similar specialized institutions $(12,13)$. KM can be utilized in the teaching and growth of nursing (10). One of the most important stages of KM is the storage of knowledge. In the nursing educational system, knowledge is in a constant, continuous, and dynamic flow. If available knowledge is not suitably stored in a system, it could easily be lost in different ways such as forgetting, non-usage, a change in job status, retirement, or even death. Stored knowledge can effectively safeguard an organization from knowledge loss (14). In the Iranian nursing education, nursing knowledge is gained through different ways, and considering the fact that the flow of nursing knowledge is mostly intangible and practical, the question of "how nursing knowledge is stored?" arises.

Knowledge can be seen as a capital resource that can be attained, stored, and used in educational systems. An organization's ability to preserve this knowledge helps to systematize activities and solve problems (15). The repository or storage of knowledge increases the opportunities

Copyright ( ) 2014, Iranian Red Crescent Medical Journal; Published by Kowsar. This is an open-access article distributed under the terms of the Creative Commons Attribution-NonCommercial 4.0 International License (http://creativecommons.org/licenses/by-nc/4.0/) which permits copy and redistribute the material just in noncommercial usages, provided the original work is properly cited. 
to utilize the knowledge precisely and entails a deeper and broader level of theoretical and clinical learning. It should be added that preservation of knowledge is an important step in the implementation of appropriate KM. In the Iranian nursing education, knowledge is attained and some of it is used, but more of it is free and remains unused in some ways such as non-usage, changes in job status, forgetting, retirement, or even death. Therefore, regarding the importance of KM in nursing education, it is essential to explore the process of knowledge storage in this academic field. Few articles have focused on experiences related to preservation of nursing knowledge, which makes this subject rather unfamiliar. Thus, a study concerning that issue has gained importance.

\section{Objectives}

This study aimed is to explore the elements and dimensions of the phenomenon of nursing knowledge repository within the nursing education.

\section{Materials and Methods}

Since the preservation of knowledge is a subjective concept, an inductive qualitative content analysis was used to identify the varying viewpoints and experiences of the participants. This approach improved the comprehension of data in the study (16). In inductive content analysis, the codes are extracted from the data and new concepts pertaining to the phenomenon under scrutiny emerged. We have used the conventional content analysis procedure in this research and it helped categories to be extracted directly from the data (17). In the analysis, data is scrutinized, charted, and arranged based on main subjects and themes using five stages: familiarization, identifying a thematic framework, indexing, charting, and mapping and interpretation (18).

\subsection{Data Collection}

In qualitative research, the samples include participants who not only have knowledge and experiences regarding the phenomenon under study but also show a willingness to share it (19). In this study, stratified purposeful sampling and theoretical sampling were used. According to Patton, purposeful samples can be stratified by selecting certain cases that differ regarding a main dimension. In this study samples were selected based on nursing educator and nursing student (20). The participants comprised of nursing educators and students from the Nursing and Midwifery Faculty. All nursing educators and students were eligible to participate in the study except those who reluctant to participating in the interviews. In this study, all the eligible cases accepted to participate. Participants of different age, sex, experience, educational level, and background contributed to more accurate as well as deeper information and richer variation of the phenomena under study. A total of 15 interviews were executed in the research; eight with nursing educators and five with students (two interviews were repeated). The data was gathered through semi-structured interview. One of the strong points of the study was the utilization of the valid semi-structured interview format. First, two interviews were performed as pilot interviews; then they were reviewed and validated by two expert supervisors, associate professors, and specialists in nursing and in the fields of content analysis and KM. It was best in terms of structure validity and integrity of fitness indexes (21). Interviews lasted between 45 to 125 minutes. The interviews were recorded after getting the consent of the participants, transcribed verbatim, and analyzed using the Maxqda 2010 software.

\subsection{Analysis of Data}

A five-stage framework approach was used in data analysis:

1) Familiarization stage; the researcher immersed in data by listening to the recordings and reading transcripts carefully to know the main idea and recurrent themes.

2) Identifying; a thematic framework stage where the researcher classified all the main subjects, concepts, and themes from which the data could be scrutinized and referenced, which product detailed index of labeled data. This stage was conducted via questioning and through the respondent's views or experiences about issues. The data was labeled and then checked by the supervisors.

3) Indexing stage; the thematic framework was used and all the data was converted into textual form by annotating the transcripts. Then the numerical system was used for indexing the references through the Maxqda 2010. All of these were supported by short explanations to elaborate on index heading and each of them contained large number of subthemes.

4) Charting stage; the data was rearranged based on appropriate parts of the thematic framework, which was used to form charts. In other words, the data were lifted from their original textual context and were placed in charts that consisted of the headings and subheadings from a prior research.

5) Mapping and interpretation stage; conceptual map and range of phenomena were described; different themes and their relationships were constructed to interpret findings based on the study objectives (18).

\subsection{Data Trustworthiness}

Prolonged engagement of the authors in the faculty, proved the credibility. Other factors that assisted the achievement of the same included ample contact with participants, verification of the written texts of the interviews through member checking, using memos and having the quality of the extracted codes evaluated by various experts, and not being involved in the research. Participants with high variation enhanced credibility. Peer checking was used to check dependency. Moreover, 
to achieve trustworthiness, the labeling, findings, and the interpretation of the data analysis was explained accurately and reviewed by two expert supervisors, associate professors, and specialists in the field of content analysis and educational management. Furthermore, a rich and dynamic presentation of the findings with appropriate quotations enhanced transferability(22).

\subsection{Ethical Considerations}

Before the data collection began, the study was approved by Reviewer Board of the Nursing and Midwifery Faculty and then by Medical Research Ethical Committee of the University (16.04.2012, No. 910664). Consent for participating in the interviews and permission for recording the same were taken from the subjects, the right of withdrawal from the interview at any time was given; anonymity, confidentiality, and ethical deliberations were considered in all the interviews as well as in the publication.

\section{Results}

Four male and four female educators (overall, 8) and three female and two male students of Bachelor's, Master's, and PhD degrees were included. Total sample size was 13, and 15 interviews were conducted. The two main themes of this study consisted of preservation of subjective knowledge (software) and preservation of objective knowledge (hardware). In the subjective type, the knowledge is retained in the memory (brain) whereas in the objective type, it is stored using different tools.

\subsection{Storage of Subjective Knowledge (Software)}

In the main theme of preservation of subjective knowledge, implicit knowledge was retained in the memory. Within this theme, the subthemes of storage of knowledge by the nurse educators, storage of theoretical knowledge by the students, efforts by nurse educators to store knowledge, storage of research knowledge, clinical knowledge storage by students, and storage of knowledge in the nursing education can be found.

\subsubsection{Preservation of Knowledge by Educators and Stu- dents}

\subsubsection{Knowledge Storage by Educators}

The analysis of data showed that the nursing educator had preserved the needed nursing knowledge pertaining to the different sections of the faculty environment, clinic, rules and regulations, communication, and methods for executing the mind process in the profession. They increased their level of awareness by storing knowledge, as one of the participants stated:

"Experiences can be retained in oneself for the future to be used elsewhere. Even if I don't have to teach the same subject, there are other subjects, and you use those experiences in other classes" (educator participant No. 3). Moreover, through experience, more knowledge would be added to the same and would be stored as collective knowledge. Two main reasons helped to retain the knowledge longer in the minds of the nursing educators, making them competent: a) activity in a specific field; and b) applicability of the knowledge in clinical nursing.

\subsubsection{Knowledge Storage by Students}

The students created and stored new knowledge by deliberating on the topics of nursing knowledge, presenting and storing new structure of knowledge in their minds, and through what they gained from their environment. According to one of the participants:

"If I had those notes of mine, it would have been great; I feel I can innovate. I have the notes somewhere. When you place them next to each other and use items from each, new ideas come to your mind" (student participant No.1). The intensive assignments in classes and internship facilitated the storage of nursing knowledge (concepts, skills, and care-provision models) in students' minds.

\subsubsection{Clinical Knowledge Storage by Students}

The analysis of data showed that clinical education assisted an appropriate transfer and storage of more implicit rather than explicit knowledge in the minds of the students. The students learnt techniques from their clinical instructors and then performed the exercises that would expedite storage of that knowledge. In nursing education, not much emphasis was laid on the subject of transferring professional ethics to students, as a participant claimed:

"Does the system teach students ethical behavior? No, it does not. In fact, it teaches them techniques. However, when there is no professionalism, technique alone is not an advantage. In professional ethics, the conscience matters, right? When I don't strengthen this part, I might teach him countless techniques and when he faces a challenge, he gives in" (educator participant No. 6).

when practicing and giving clinical care, the students initially looked at patients as tools and after passing some stages and acquiring experience, exhibited a more comprehensive and humane viewpoint on patients.

\subsubsection{Efforts of Nursing Educators to Transfer and Pre- serve Knowledge in Students' Memories}

One of the main activities of the nursing educators was to provide students with opportunities for storage of knowledge. In their process of exchange with the students, some educators created circumstances in which the students could start thinking, receive the new knowledge, and store it. In that regard, another participant cited:

"The knowledge is in my mind and when I say it in class, 
the students take notes; it is stored in their minds. The knowledge, which is mostly implicit, dwells in the brain" (educator participant No.11).

The nursing educators were on different levels concerning preservation of nursing knowledge in the minds of the students. The more the exchange between educator and student took place, the more the knowledge was preserved in the students' minds.

\subsubsection{Storage of Investigative (Research) Knowledge}

Since most of the nursing educators were constantly involved in research or publishing articles, the present research knowledge not only broadened the scope in the educator but also was stored as research experience and used later in further research works. Students entering research programs in their $\mathrm{PhD}$ and Master's degree courses would be guided by their instructors when making their proposals with such precision that research knowledge would get stored; as one of the participants said:

"When you would ask them (the advisors) a question, they would bring up further questions in your mind forcing you to go after the answer yourself. Therefore, I would find my answer there and return with it to him. Then he would clarify it further" (student participant No.3).

\subsubsection{Storage of Knowledge in Nursing Education}

The analysis of data regarding the experience of the participants showed that more knowledge was stored and developed individually by each one of the educators. This is the experience stated by one participant:

"In my opinion, knowledge is static in the nursing faculty; it doesn't have a flow. Perhaps each individual does have knowledge to himself. But we do not have anything that is organizational; it would be useful only to oneself" (student participant No. 1).

One of the important matters was the preservation of knowledge within nursing education, especially in those who had gained a lot of experience in the different aspects of teaching and were retired, had changed status, or had died. A change in status would cause knowledge to be taken out of the organization. One participant affirmed this by saying:

"It is expected that the working schedule of a newcomer should differ with that of someone 25 years in the service. No effort is made to reap the benefits of valuable experiences of people who the system itself has spent on them" (educator participant No. 8).

Another dimension of knowledge storage in nursing education included preservation of the educators' knowledge and experience concerning teaching methods, caregiving techniques, communications, and professional relations.

\subsection{Storage of Objective Knowledge (Hardware)}

Data analysis regarding storage of explicit knowledge showed that objective knowledge was stored in this sec- tor. Explicit memory storage was composed of instruments and methods that stored and executed this kind of knowledge. The instruments of storage were classified as electronic storage and paper storage whereas the storage methods were individual and the general types of storing knowledge.

Educators stored explicit knowledge for their own or general use in notes and would save electronic files to preserve individual experiences and personal findings. On their part, the students would take notes when studying from texts and would record any exchange of ideas that they thought could be utilized in the future. One of these participants indicated:

"Something related to requirements would come to my mind, which I would note down next to the material I was reading so that I wouldn't forget interesting things that could be used in a new way or could be a good experience" (student participant No.1).

Further, with regards to preservation of knowledge of a more general dimension, nursing knowledge was classified and stored as per usage and type in journals, books, theses, investigative researches, and literature in either electronic or paper forms.

\section{Discussion}

The storage of knowledge plays an important role in the execution of KM and in the reutilization and production of knowledge. Analysis of the data showed that most of the educational activities of the nursing educators occurred in the faculty and clinic environments. Being present in such live environments during performing their educational activities, led to transfer of nursing knowledge to the others, consciously or unconsciously, and helped to its storage. Simon has cited that individuals are the best means for storing organizational experience (23). In the present study, the educators gained proficiency on the subject content and work methods over time. Noam concluded that the response of organizations to an increase in the amount of knowledge showed itself in raising qualification, better education, reorganizing knowledge, and goal-oriented specialization (24). Our study is in line with the viewpoint of Noam, who found that storage of knowledge manifested itself as increased experiences, professional qualifications, and expertise. In other words, knowledge and talents are capabilities that make up the main feature of the nursing staff's activities and are essential grounds for high-performance in nursing (21). In Iran, the educational programs for the nursing students were quite intensive and knowledge was accumulated through the assignments, performed exercises, and the exchange in their subjects. In accordance with the views of Oakley, knowledge gets codified and stored, and by using the same, the students are directed toward the next stage, i.e. accumulation of data (25). This knowledge would merge with previous knowledge at times and new knowledge would be formed 
and stored in their minds. McCutchen concluded that preservation of knowledge results in more expert and advanced performance by the students (26). Vahedi et al. stated that tacit knowledge could be the knowledge that underlies the individual qualification, personal models, concepts, processes, and management systems (27). Our research, showed the through the course of their studies, the nursing students would gradually get ready for attaining and storing clinical and professional knowledge by preserving theoretical knowledge, concepts, and processes of clinical nursing and care-giving models in their minds.

The nursing educators created the necessary background for preservation of knowledge through designing suitable questions, introducing references, debating, giving logical talks, focusing on the subject of study, and avoiding peripheral matters during their exchanges. Clinical training provided the students with the opportunity of storing the existing knowledge of clinical science through direct contact with patients and exchange with educators. According to Elliot and Wood's view, tacit and explicit knowledge, which are forms of mental and practical knowledge (28), are processed and stored by students in learning opportunities, practical work, and sharing of experiences; thus, the knowledge is preserved more deeply and at a higher level. Nursing students must also store different subjects in their field based on emotional intelligence, which comprises the capability to observe one's own and others' emotional states (Morrison, 2008), that not only plays a vital role in outstanding job performance but also provides an exceptional environment for the provision of supply (29). Spencer stated that interactive learning is a practical way for facilitating recognition and precise, technical, simultaneous, continuous learning in students (30).

Nonetheless, clinical training did not provide suitable grounds for the preservation of knowledge in the affective domain and professional ethical field. Borhani et al. stated that no new approaches existed for ethical training in nursing education and the old ones did not meet the requirements of the nurses (31). The present research was also in line with the studies of Borhani et al. In addition to doing research, the educators would assemble and store the knowledge they found while referring to literature in their investigative work. Coghlana and Paul confirmed that research activities provide the scholars with scientific methods, solid classification, and the execution and production of knowledge (32). Prominent educators who had gained and preserved valuable knowledge on different subjects took the knowledge out of the faculty with them when retiring or changing position. Officials in charge of nursing education should take measures to prevent this knowledge from leaving and to store the same within the faculty. In this way, others can make use of that knowledge without need to connect with those who had gained the knowledge first. According to Jasimuddin, preserved knowledge can shield a sys- tem well from failing to remember and from the anxiety arising from exhaustion (33).

In the present study, the educators preserved the knowledge mostly within isolated experiences rather than within the nursing education system as a whole. Walsh and Ungson stated that knowledge is preserved in the stores of the individual, culture, changes and metamorphoses, and constructs (34). The knowledge that remains in an organization and within the heads of the members of that organization is more beneficial than the embedded knowledge in single minds. Schulte et al. confirmed that preservation of knowledge occurs through guidance, books, journals, articles, databases, government documents, organizational publications, and university sites as well as through execution of methods and standard procedures (13). Standards are also considered as important knowledge repositories in the nursing profession. Health promotion-related standards are established in five domains: Management policy; patient assessment; patient information and intervention; promoting a healthy workplace; and continuity and cooperation. Utilizing the set of standards is a key approach to increasing quality in healthcare (35).

Rahmani et al. stated that knowledge can be stored in educational material banks for using later (36). In our study, the storage of explicit knowledge took place with the objective of being retrieved later by oneself or others. The educators and students stored explicit knowledge in electronic files. Technologies such as engine processes can be applied to preserve knowledge in knowledge depositories. Then, retrieval systems can be utilized to extract knowledge from these depositories or sources for human processes (37). In this study, the preservation took place for personal/informal use and for general/more formal use. Allameh et al. mentioned using information technology to store knowledge in different forms, e.g. literature, electronic databases, and bulletin boards (38). Knowledge storage systems must have factors such as structure, classification, policies, and procedures to provide accurate, correct, and timely information according to the needs of the learners. According to the analysis of our research, information was stored in an informal or individual form for personal use and on paper and electronic documents to make it more accessible. However, in the nursing education system, knowledge was formally stored electronically on a larger scale in databases, the university site, faculty journals, or in paper form in archived thesis or textbooks in the library for general accessibility. Tian et al. also cited knowledge retention units such as databases, references, and books (39). Knowledge can be gained and stored in retention units and be made more easily accessible to others using information technology (40). In this research, the students had access to databases and support systems had facilitated storage and accessibility. The more the educators and students used the knowledge storage system, the greater the effectiveness of the nursing knowledge was. Plans must 
be made to convert implicit knowledge into explicit one and to preserve them in the faculty's storage units. The experiences and intellectual capital of the experienced educators, who are changing status or retiring, must be preserved within the nursing educational system before their departure. In this way, people who need the same in different learning and clinical situations can gain access to it without having to get in contact with the people who had gained the knowledge first. This will improve education, restructure goal-oriented knowledge, promote qualification of learning, and increase proficiency in clinical performance by the students.

Finally, regarding the culture of professional ethics in nursing, to foster professional behavior and responsibility in the students, emotional objectives should be added to the nursing curriculum and put into practice. The faculty should create different clinical and theoretical situations to transfer and practice technical knowledge during theoretical situations and internship as well as to provide ground to store and use ethical knowledge by presenting emotional objectives. This study reveals nursing knowledge storage through concept analysis that can be used in other nursing educational systems but cannot generalize other noneducational contexts.

\section{Acknowledgements}

This article was part of a PhD thesis in nursing that has been accepted and registered under Code No. 910664 on April 17, 2013 by the Vice Chancellor of Research and confirmed by the Ethics Committee of the Mashhad University of Medical Sciences. We hereby would like to extend our gratitude to the Mashhad University of Medical Sciences for its financial support for this research. Moreover, we thank all the respectful participants and the staff of the Nursing and Midwifery Faculty of Mashhad as without their cooperation and support, this study would not have been possible.

\section{Funding/Support}

This research was supported through rewarded study leave from Mashhad University of Medical Sciences.

\section{References}

1. Laal M. Knowledge management in higher education. Procedia Comput Sci. 2011;3:544-9.

2. Bhatt GD. Knowledge management in organizations: examining the interaction between technologies, techniques, and people. $J$ Knowl Manag . 2001;5(1):68-75.

3. Huang LS, Quaddus M, Rowe AL, Lai CP. An investigation into the factors affecting knowledge management adoption and practice in the life insurance business. Knowl Manag Res Prac. 2011;9(1):58-72.

4. Hsia TL, Lin LM, Wu JH, Tsai HT. A framework for designing nursing knowledge management systems. Interdiscip J InfKnowl Manag. 2006;1(1):13-23

5. Smith M, McCarthy MP. Disciplinary knowledge in nursing education: going beyond the blueprints. Nurs Outlook. 2010;58(1):44-51.

6. Han X, Zhou Q, Yang J. A Technical Mode for Sharing and Utiliz ing Open Educational Resources in Chinese Universities. Know
Manag Learn Int J. 2011;3(3):356-74

7. Rodgers BL. Developing Nursing Knowledge, Philosophical Traditions and Influences.: Lippincott Williams and Wilkins;2005.

8. Neef D, Siesfeld GA, Cefola J. The economic impact of knowledge.Woburn: Butterworth Heinemann;1998.

9. Zhao J. School knowledge management framework and strategies: The new perspective on teacher professional development. Comput Human Behav. 2010;26(2):168-75.

10. Hautala J. International academic knowledge creation and ba. A case study from Finland. Knowl Manage Rese Prac. 2011;9(1):4-16.

11. Brooks F, Scott P. Knowledge work in nursing and midwifery: An evaluation through computer-mediated communication. Int $J$ Nurs stud. 2006;43(1):83-97.

12. Risjord M. Nursing Knowledge: Science Practic and Philosophy. Wi ley- Blackwell; 2010.

13. Schulte PA, Lentz TJ, Anderson VP, Lamborg AD. Knowledge management in occupational hygiene: the United States example. Ann Occup Hyg. 2004;48(7):583-94.

14. Argote L, Beckman SL, Epple D. The persistence and transfer of learning in industrial settings. Manage Sci.1990;36(2):140-54.

15. Olivera F. Memory systems in organizations: an empirical investigation of mechanisms for knowledge collection, storage and access. J Manage Stud. 2000;37(6):811-32.

16. Elo $\mathrm{S}$, Kyngas $\mathrm{H}$. The qualitative content analysis process. $J \mathrm{Adv}$ Nurs. 2008;62(1):107-15.

17. Moretti F, van Vliet L, Bensing J, Deledda G, Mazzi M, Rimondini $\mathrm{M}$, et al. A standardized approach to qualitative content analysis of focus group discussions from different countries. Patient Educ Couns. 2011;82(3):420-8.

18. Srivastava A, Thomson SB. Framework analysis: a qualitative methodology for applied policy research. JOAAG. 2009;4(2):72-9.

19. Schreiber RS, Phyllis Noerager Stern. Using grounded theory in nursing.New yourk: Springer; 2001.

20. Patton MQ. Qualitative evaluation and research methods.Beverly Hills: SAGE Publications inc; 1990.

21. Najarkolaei FR, Niknami S, Shokravi FA, Tavafian SS, Fesharaki MG, Jafari MR. Sexual behavioral abstine HIV/AIDS questionnaire: Validation study of an Iranian questionnaire. J Educ Health Promot. 2014;3:10.

22. Polit DF, Beck CT. Nursing research: Generating and assessing evidence for nursing practice: Lippincott Williams \& Wilkins;2008.

23. Simon HA. Bounded rationality and organizational learning. Organ Sci. 1991;2(1):125-34.

24. Noam EM. Electronics and the Dim Future of the University. Sci. 1995;270(5234):247-9.

25. Research evidence, knowledge management in education and learning. High-level Forum on Knowledge Management in Education and Leading. EPPI-Centre and Social Science Research Unit. 2002.

26. McCutchen Deborah. Knowledge, Processing, and Working Memory: Implications for a Theory of Writing. Educ Psychol. 2010;35(1):13-23.

27. Vahedi M, Ali NH, Irani F. Information technology (IT) for knowledge management. Procedia Comput Sci. 2011;3:444-8.

28. Elliot D, LoBiondo Wood G. Nursing Research Methods critical Appraisal and Utilization: Mosby Electronic Resource Links \& Information Network.

29. Rushdy Mohamed F, Ramzy Yousef H. Emotional Intelligence and Conflict Management Styles among Nurse Managers at Assiut University Hospitals. J Educ Pract. 2014;5(5):160-5.

30. Spencer L. Motivating Students to Learn through the Interactive Learning Model. J Health Educ. 1998;29(5):277-81.

31. Borhani FAF, Mohammadi A, Abbaszadeh A. Needs and challenges facing the teaching of ethics Competence of professional ethics for nurses. J Med Ethics Hist Med. 2008;3(2):27-38.

32. Coghlana D, Paul C. Notes toward a philosophy of action learn ing research. Action Learn Res Pract . 2010;7(2):193-203.

33. Jasimuddin SM. An integration of knowledge transfer and knowledge storage: an holistic approach. Comput Sci Eng. 2005;18(1):37-49.

34. Walsh JP, Ungson GR. Organizational memory. Acad Manage Rev 1991;16(1):57-91. 


\section{Karimi Moonaghi Het al.}

35. Yaghoubi M, Javadi J. Health promoting Hospitals in Iran How it is? J Educ Health Promot. 2013;2(41).

36. Rahmani M, Wong BW, Ang L, Cheung CC, Carthy JM, Walinski $\mathrm{H}$, et al. Versican: signaling to transcriptional control pathways. Can J Physiol Pharma col. 2006;84(1):77-92.

37. Chan JO. Integrating knowledge management and relationship management in an enterprise environment. Commun IIMA. 2014;9(4):37-52.
38. Allameh M, Zamani M, Davoodi SMR. The relationship between organizational culture and knowledge management:(A case study: Isfahan University). Procedia Comput Sci. 2011;3:1224-36.

39. Tian J, Nakamori Y, Wierzbicki AP. Knowledge management and knowledge creation in academia: a study based on surveys in a Japanese research university. J Knowl Manage. 2009;13(2):76-92.

40. Zhu B. Information visualization for knowledge repositories Applications and impacts. Ann Arbor: The University of Arizona; 2002. 